\title{
Elucidating morphological effects in membrane mineral fouling using real-time particle imaging and impedance spectroscopy
}

\author{
Chidiebere S. Nnebuo, Denise Hambsch, Oded Nir ${ }^{*} \bowtie$
}

\section{Department of Desalination and Water Treatment, Zuckerberg Institute for Water}

Research, Jacob Blaustein Institutes for Desert Research, Ben-Gurion University of the Negev, Sede-Boqer Campus 84990, Israel

${ }^{*}$ Corresponding author $\bowtie$ odni@bgu.ac.il

\section{Abstract}

Mineral fouling is a major hindrance to high recovery effluent nanofiltration, with calcium phosphate $(\mathrm{Ca}-\mathrm{P})$ and calcium carbonate $\left(\mathrm{CaCO}_{3}\right)$ the most prevalent mineral foulants. In this study, we used a novel combination of real-time in-line microscopy, electrical impedance spectroscopy (EIS), post SEM analysis, and filtration metrics (water flux and rejection) to study mineral fouling mechanisms of $\mathrm{Ca}-\mathrm{P}$ and $\mathrm{CaCO}_{3}$ salts in synthetic effluent nanofiltration. We used nanofiltration (NF) polyelectrolyte multilayer (PEM) membranes, prepared by static layer-by-layer (LbL) coating of a cationic polymer - polydiallyl dimethylammonium chloride, and anionic polymer - poly styrenesulfonate (six bi-layer) on a polyethersulfone (PES) ultrafiltration (UF) membrane. Increasing permeate recovery over filtration time was simulated through additions of $\mathrm{CaCl}_{2}$ with $\mathrm{NaHCO}_{3}$ or $\mathrm{NaH}_{2} \mathrm{PO}_{4} / \mathrm{Na}_{2} \mathrm{HPO}_{4}$. Using the novel combination of methods, we delineated the mechanisms governing fouling development with time for both $\mathrm{CaCO}_{3}$ and $\mathrm{Ca}-\mathrm{P}$. For $\mathrm{CaCO}_{3}$, a transition from heterogeneous precipitation on the membrane surface (scaling) to particulate fouling due to bulk precipitation was identified. For Ca-P, a transition from fouling by amorphous particles to fouling by crystalline particles was identified; and this phase-change was captured in real-time images using an in-line microscope. We also found that for similar precipitation potentials measured by weight, Ca-P fouling was more detrimental to water flux (86\% 
28 decrease) compared to $\mathrm{CaCO}_{3}(20 \%$ decrease) due to the voluminous amorphous phase. We

29 established in-line microscopy as a new useful method to study mineral fouling, as it gives

30 invaluable information on the suspended particles in real-time. Combining it with EIS gives

31 complementary information on mineral accumulation on the membrane surface. Insight from

32 this study and further use of these methods can guide future strategies towards higher effluent

33 recovery by membrane filtration.

34 Keywords: membrane scaling; effluent nanofiltration; calcium phosphate; calcium

35 carbonate; in-line microscopy;

\section{1. Introduction}

38 Recycling of wastewater has a vital role in tackling global water scarcity, as the effluent is a

39 largely untapped water resource with stable supply year-round (Almuktar et al., 2018;

40 Farhadkhani et al., 2018; Friedler, 2001; Oron et al., 2008; Tran et al., 2016). However,

41 wastewater effluent contains various persistent contaminants that pose a risk to public health

42 and the environment (Garcia and Pargament, 2015; Grandclément et al., 2017; Murgolo et

43 al., 2019; Wintgens et al., 2005). These contaminants may include excess phosphorus,

44 emerging/trace organic contaminants (ECs/TrOCs) such as pharmaceuticals and personal

45 care products (PPCPs), endocrine disrupting compounds (EDCs), trace elements

46 (Grandclément et al., 2017), steroid hormones, surfactants, industrial chemicals (Luo et al.,

47 2014), pesticides and inorganic salts (Wintgens et al., 2005). Since conventional water

48 treatment plants cannot properly remove these contaminants (Luo et al., 2014; Nghiem and

49 Fujioka, 2016), it is widely acknowledged today that further treatment is needed for

50 sustainable reuse and safe discharge of tertiary effluent.

51 To attain various water quality requirements necessary for different wastewater recycling

52 uses, membrane processes like reverse osmosis (RO) and nanofiltration (NF) have emerged 
53 as the best available technology (Bunani et al., 2013; Lee and Lee, 2005; Mohammad et al., 54 2015; Nghiem and Fujioka, 2016; Wintgens et al., 2005). RO membranes reject most 55 dissolved molecules and thus can bring the tertiary effluent to drinking-water quality level, 56 enabling potable use, either directly (e.g., Singapore) or indirectly through aquifer recharge 57 (e.g., California). NF membranes remove all microorganisms and most of the organic 58 micropollutants and dissolved phosphorus (depending on membrane type). Therefore NFtreated effluent can be exploited in non-potable uses such as irrigation, rehabilitation of water supply to natural water bodies (Garcia and Pargament, 2015; Oron et al., 2008), and creating artificial water bodies for recreational activities or ornamentation. While RO is the standard

62 for potable reuse of tertiary effluent, using NF membranes offer some leverage over RO membranes in non-potable reuse; including lower operating pressure, tuneable selective removal of salts/solutes, and the availability of more robust membrane materials (Mohammad et al., 2015; Nir et al., 2018; Schäfer et al., 1998). Therefore, in light of the global increase in wastewater reuse and stricter effluent discharge regulations, the application of RO and NF

67 processes for wastewater treatment is expected to increase. of retentate stream management (Chang et al., 2009; Greenlee et al., 2010; Kappel et al., 2014; Voutchkov, 2011). A retentate stream of RO/NF applied to wastewater, typically 10$30 \%$ of the feed water volume, contains the various contaminants removed from the effluent

72 at higher concentrations. Therefore, there is a need to minimize the retentate volume by operating at a higher permeate recovery ratio to achieve cost-effective and sustainable $\mathrm{RO} / \mathrm{NF}$ processes. However, the recovery ratio in effluent NF/RO is currently limited by chemical fouling, mainly caused by the precipitation of calcium phosphate (Ca-P) and calcium carbonate $\left(\mathrm{CaCO}_{3}\right)$ minerals (Greenberg et al., 2005), reaching supersaturation when

77 concentrated in the retentate. Commonly used strategies for scaling control can be grouped 
into (a.) scalants removal by pre-treatment of feedwater (b.) scaling inhibitors use (c.) process-based strategies (Tong et al., 2019). While, $\mathrm{CaCO}_{3}$ scaling can be effectively controlled by adjusting the $\mathrm{pH}$ and use of antiscalants (Chaussemier et al., 2015), Ca-P minerals could precipitate at $\mathrm{pH}<6$, and no effective antiscalants are currently available for controlling Ca-P fouling (Antony et al., 2011; Greenberg et al., 2005; Mangal et al., 2021; Steiner et al., 2010). Developing novel solutions calls for a better understanding of the chemical fouling mechanisms of these scalants during effluent filtration.

Mineral fouling occurs when sparingly soluble salts are rejected by the membrane, and consequently, their concentration increases in the retentate until it reaches a supersaturation

87 level that is sufficiently high to induce crystallization (Tong et al., 2019). Supersaturation is further increased near the membrane surface due to concentration polarization $(\mathrm{CP})$ (Antony et al., 2011; Lee and Lee, 2005, 2000; Van De Lisdonk et al., 2000). The evolution and dynamics of mineral scaling are influenced by several factors including, $\mathrm{pH}$ (Klepetsanis and 91 Koutsoukos, 1989), flow velocity (Lee and Lee, 2000), Ca/P ratio, presence of other salts $92\left(\mathrm{Mg}^{2+}\right.$ for $\left.\mathrm{CaCO}_{3}\right)($ Chen et al., 2006; Roques and Girou, 1974), operating pressure (Lee and 93 Lee, 2000), physicochemical membrane surface properties (Rathinam et al., 2018), and ion rejection rate (Kaganovich et al., 2019). Mineral fouling can progress through homogeneouslayer grows laterally on the membrane surface.. Tzotzi et al. (2007) identified heterogeneoussurface crystallization as the primary mechanism for $\mathrm{CaCO}_{3} \mathrm{NF}$ scaling of tap water, while $\mathrm{Xu}$ et al. (2010) reported colloidal fouling as the primary mechanism of Ca-P salt in nanofiltration of effluent. While both routes can hinder filtration performances, removing a scaling is typically more challenging or even not practical (Antony et al., 2011). 
103 Although mineral fouling is affected by processes occurring both in the retentate and on the membrane surface, there are little or no reports on parallel measurements of these processes.

105 Such data can, for instance, delineate between scaling and particulate fouling. Moreover, 106 little or no attention was given to the role of mineral morphology in effluent nanofiltration. 107 Elucidating morphological effects can be challenging, especially for Ca-P minerals, 108 including multiple possible phases of different morphologies. We used a novel combination 109 of in-line real-time particle microscopy and in-situ electrochemical impedance sectroscopy 110 (EIS) to address these knowledge gaps. We conducted nanofiltration experiments, where we 111 gradually added scaling ions to simulate the increase in supersaturation and the accumulation 112 of crystal mass associated with mineral fouling. The data collected from these novel systems, 113 together with water and salt permeation data and post-filtration electron microscopy, 114 elucidated the underlying micro-scale phenomena and the mechanistic differences between 115 the two mineral types studied here. These differences affected the membrane performance 116 and pointed toward different mitigation methods for $\mathrm{Ca}-\mathrm{P}$ and $\mathrm{CaCO}_{3}$ mineral fouling.

\section{$118 \quad 2 . \quad$ Materials and method}

\section{2.1. Materials}

120 The following chemicals were obtained from Merck company the U.S.A.; $\mathrm{MgSO}_{4} \cdot 7 \mathrm{H}_{2} \mathrm{O}$; $121 \mathrm{KCl} ; \mathrm{CaCl}_{2} \cdot 2 \mathrm{H}_{2} \mathrm{O} ; \mathrm{NaCl} ; \mathrm{Na}_{2} \mathrm{HPO}_{4} \cdot 2 \mathrm{H}_{2} \mathrm{O} ; \mathrm{NaH}_{2} \mathrm{PO}_{4} \cdot \mathrm{H}_{2} \mathrm{O}$ while $\mathrm{NaHCO}_{3}$ and Nitric acid $122(70 \%)$ were obtained from Bio-lab company Israel; AnalaR BDH Laboratory Supplies Israel 123 supplied $\mathrm{Na}_{2} \mathrm{HPO}_{4}$; Sigma Aldrich supplied $\mathrm{NaH}_{2} \mathrm{PO}_{4}$. All chemicals were of analytical grade. $\mathrm{Na}_{2} \mathrm{HPO}_{4}$ and $\mathrm{NaH}_{2} \mathrm{PO}_{4}$ were used to make a phosphate buffer of $0.1 \mathrm{M}$ (at a pH 7) in 125 the ratio of $0.65: 0.35$. The phosphate buffer was used throughout the experiments for membrane integrity P rejection tests. Polyethersulfone (PES) ultrafiltration (UF) membranes 
with molecular weight cut-off (MWCO) of 20kDa was obtained from Sterlitech U.S.A; Polydiallyldimethylammonium chloride (PDADMAC) $\mathrm{MWCO}=400-500 \mathrm{kDa}$ and Poly(styrenesulfonate) (PSS) MWCO = $1000 \mathrm{kDa}$ were also purchased from Sigma Aldrich

130 while deionized (DI) water $<2 \mu \mathrm{S} / \mathrm{cm}$ was used during the experiments. The procedure for 131 layer-by-layer coating of PES membrane into an NF polyelectrolyte multilayer membrane 132 (PEMM) is available at supporting information (SI) S1.0.

\subsection{V19 particle view microscope}

V19 Particle view ${ }^{\mathrm{TM}}$ Mettler Toledo AG (U.S.A) is a probe-based video microscope and an in-line in-situ tool for real-time monitoring of the particle development in the feed during filtration. Particle V19 (iC PVM) measurement is a particle vision measurement (PVM) technology - a non-invasive tool that can capture and visualize particles development in realtime. $\mathrm{iC}$ PVM emits a laser that illuminates the particles within the microscope probe window, and particles reflect the laser into the probe. The probe captures the reflected image through its camera. Each captured image has a known brightness and intensity, with the ratios of the former and later giving the reflectivity of the system as relative backscatter index

142 (RBI). iC PVM software calculates the RBI, and its analysis with captured images gives the 143 changes in the particles' shape, size, and concentration. Functional specifications of Particle 144 view V19 are $1300 \mu \mathrm{m} \times 890 \mu \mathrm{m}( \pm 50 \mu \mathrm{m})$ field of view, $>2 \mu \mathrm{m}$ optical resolution, $1500 \mathrm{x}$ 1451024 pixels image resolution, and eight pulsed laser diodes (4 front; 4 back) illumination. 146 Settings used during the experiment are: front light with auto adjust, the focus was moved $147100 \mu \mathrm{m}$ away, with sharpening and enhance features selected. 

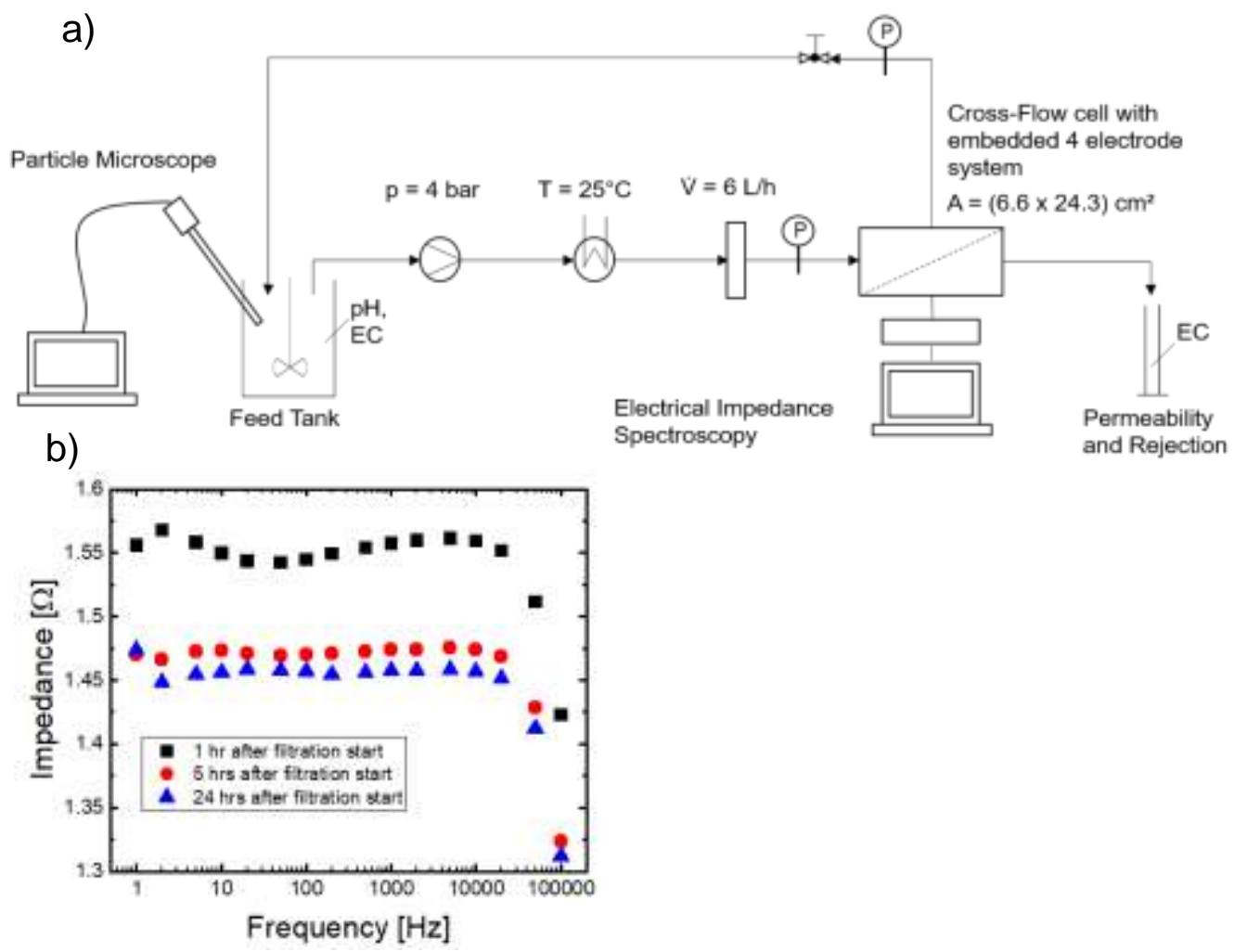

Figure 1: (a) Schematic of the nanofiltration experimental set-up with in-line particle microscope and insitu electrical impedance spectroscopy, enabling real-time monitoring of mineral fouling. (b) Typical EIS scan of the entire frequency range $\left(1-10^{5} \mathrm{~Hz}\right)$, which was similar for all experiments. Data shown for $\mathrm{CaCO} 3$ mineral scaling under low supersaturation. Weak dependence on frequency was demonstrated, with lower frequencies $(1-10 \mathrm{~Hz})$ generally being the most stable. Frequency $\omega=5 \mathrm{~Hz}$ was selected.

153 All experiments were performed in full recirculation mode, with permeate and retentate recycled into the feed tank. Concentrated synthetic wastewater effluent according to Shafdan composition (Oren et al., 2007) (Table S3) was used. Experiments were performed in three stages: (i.) compaction filtration using DI for 18 hours to achieve stable flux and minimize sample, and reference noise of the impedance spectra; (ii.) conditioning filtration - DI water was replaced with feed solution (concentrated synthetic effluent) without the scaling salt components, and filtration runs for 2 hours; and (iii.) filtration experiments - started with the addition of the scaling salts (Table S4) accordingly. PHREEQC was used to model similar mass-based precipitation potential for both scalants in each experiment for the concentration 
162 of added scaling salt components. Details about PHREEQC are available at S2.0.

163 Experimental set up (Fig. 1) has a 2L feed tank stirred with a mechanical stirrer set at 200rpm

164 throughout the experiments. The feed tank was connected via a gear pump (FluidOTech) to

165 the INPHAZE ${ }^{\mathrm{TM}}$ filtration module, which contained the membrane. The pump was coupled

166 with a frequency converter (EDS1000 Inverter, ENC), enabling the adjustment of the feed

167 flow rate. Before entering the filtration module, the solution passed through a customized

168 chiller (MRC), keeping the temperature at $25 \pm 1{ }^{\circ} \mathrm{C}$. Two gauges at the inlet and outlet of the

169 module measure the transmembrane pressure (TMP). TMP at the module's outlet could be

170 regulated by a back-pressure valve (Swagelok) from 0 to 7 bars. Additionally, retentate flow

171 was monitored by a rotameter type flowmeter (ASV Stubbe).

172 The membrane sample size for crossflow-chamber of the INPHAZE ${ }^{\mathrm{TM}}$ filtration module was

$173243 \mathrm{~mm} \times 66 \mathrm{~mm}$, giving an effective membrane area of $0.016 \mathrm{~m}^{2}$. The INPHAZETM

174 filtration module is connected with a four electrodes system which is connected to the

175 spectrometer unit and in turn connected to a computer. Our focus in using EIS was to

176 investigate dynamic scaling processes occurring over relatively short timescales. Therefore,

177 impedance measurements analysis were based on a single frequency, $5 \mathrm{hz}$ (Fig. 1b), in which

178 the dependency of impedance on frequency is weak (phase was almost zero). Therefore, at

179 this frequency, the EIS value can be considered as pure electric resistance. The same 180 approach was applied for membrane fouling in previous studies (Bannwarth et al., 2016; Nir 181 et al., 2016). The pressure for all experiments was constant at $\mathrm{p}=4$ bars with a feed flow rate 182 of $\dot{\mathrm{V}}=6 \mathrm{~L} / \mathrm{h}$. The experiments were modified according to Figures S3 and S4 to study 183 different aspects of scaling. A summary of differences in the experiments can found in Table 184 S5. Figure S5 shows the experimental cycle used for all experiments. 


\section{Results and discussion}

187 Following compaction and pre-conditioning stages, the filtration stage commenced with 188 additions of 7 aliquots of $\mathrm{CaCO}_{3}\left(\mathrm{CaCl}_{2} / \mathrm{NaHCO}_{3} ; 8 \mathrm{~mm}\right.$ each $)$ or $\mathrm{Ca}-\mathrm{P}\left(\mathrm{CaCl}_{2} / \mathrm{Na}_{2} \mathrm{HPO}_{4} ; 6\right.$ 189 and $4 \mathrm{~mm}$ each) salts respectively at 20 minutes intervals to the feed tank during $4 \mathrm{hrs}$ 190 filtration run for the high supersaturation experiments. Modifications were made to the 191 experimental procedure to investigate the different stages of fouling. Permeate flux, observed 192 salt rejection, electrical conductivity (EC), electrical impedance spectroscopy, and in-situ 193 online imaging (RBI and images) of crystal evolution in the feed tank were recorded in real194 time during all the filtration experiments.

\section{1. $\mathrm{CaCO}_{3}$ mineral fouling at high supersaturation}

197 Three distinct stages in the evolution of normalized flux and electrical resistance (Fig 2a) appeared during filtration of synthetic effluent supersaturated with $\mathrm{CaCO}_{3}$. This observation

199 is consistent with data obtained from repeat experiments (S15), indicating the reproducibility 200 of the experiments. In the first stage ( $\mathrm{t} \sim 0-1.2 \mathrm{hr}$ ), the flux decreases sharply by $25 \%$, while 201 at the same time, the electrical resistance of the fouling layer increased from $\sim 0$ to $2.5 \pm \Omega$. In 202 the second stage ( $\mathrm{t} \sim 1.2-1.9 \mathrm{hr}$ ), the flux increased by $8.0 \%$, while the electrical resistance 203 of the fouling layer increased moderately, reaching a peak of $2.7 \pm \Omega$. In the third and final 204 stage $(\mathrm{t} \sim 1.9-4 \mathrm{hr})$, the flux decreased moderately by $6.0 \%$ until $\mathrm{t}=3.35 \mathrm{hr}$ and remained 205 unchanged until the end of the experiment (4 hr). During that time, the electrical resistance 206 of the fouling layer decreased slightly, reaching $\sim 2.6 \pm \Omega$ - this complex behavior of flux and 207 electrical resistance hints that different fouling mechanisms were in action during filtration. 
208 Using real-time imaging (Fig. 2c) and light scattering (RBI) (Fig. 2b) of mineral particles in

209 the recycled feed solution in combination with the real-time electrical resistance and flux

210 measurements can underpin the dominant fouling mechanisms at each stage.

211 Our results indicate that the first stage of fouling was dominated by $\mathrm{CaCO}_{3}$ scaling, i.e.,

212 heterogeneous precipitation and crystallization of $\mathrm{CaCO}_{3}$ on the membrane surface (Antony

213 et al., 2011). The increase in fouling layer resistance is typical to scaling (Antony et al.,

214 2013) - the formation of a rigid crystalline layer that completely blocks water and ion
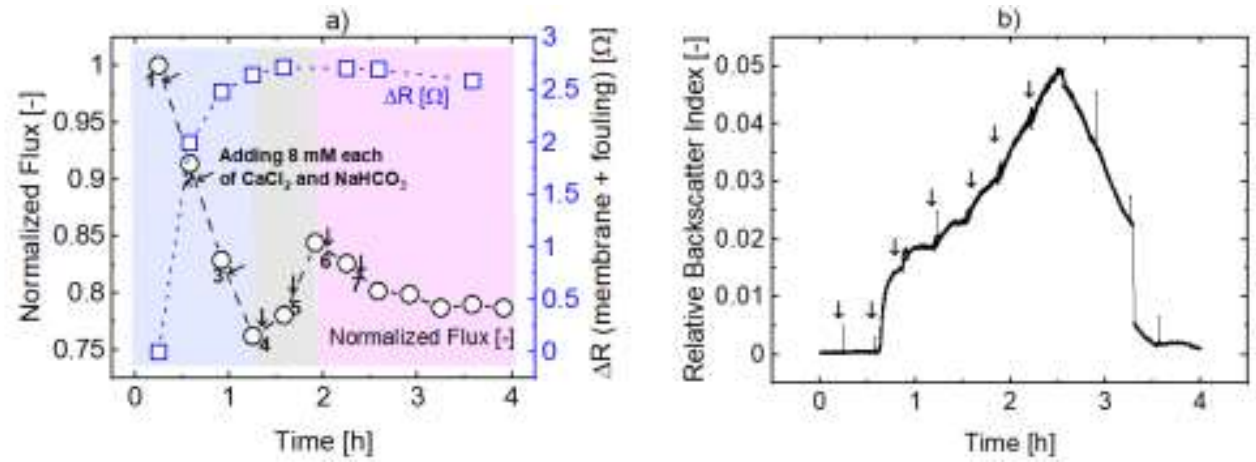

c)

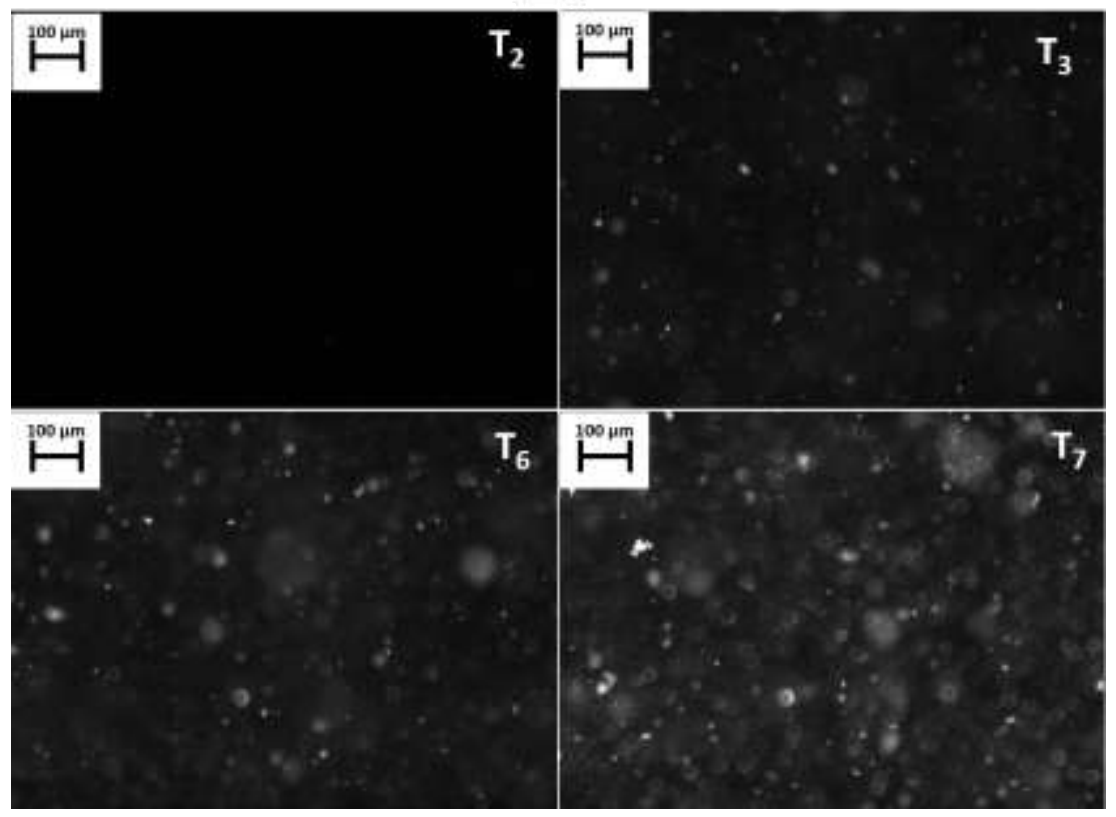

Figure 2: Data recorded during nanofiltration of solutions highly supersaturated with calcium carbonate (a) Normalized flux-(O) (arrows everywhere in all figures indicate the addition of scaling components, immediately after permeability measurement. The first point is the permeability of background solution without scaling salts, all permeability normalized to initial permeability) and membrane resistance-( $\square$ ) $[\Omega]$ (b) RBI [-] evolution, (c) and in-line real-time microscope images over the filtration time [h] for concentrated effluents NF with $\mathrm{CaCO} 3$.

215 transport through the impacted membrane surface fragment. Accordingly, the RBI (Fig. 2b) 
remained constant in the first 0.5 hours, and no particles were observed in the feed tank by

217 the in-line microscope (Fig. 2c- $\mathrm{t}_{3}$ ). The sharp increase in RBI after 0.5 hrs is likely due to the

218 formation of sub-micron crystal clusters (too small to be captured in images), marking the

219 beginning of homogeneous precipitation. These tiny particles were bound to accumulate on

220 the membrane surface and increasingly contribute to both electrical and hydraulic resistances

221 together with the scaling layer, which was likely still the dominant mechanism at $\mathrm{t} \sim 0-1.2$

$222 \mathrm{hr}$.

223 At the second stage, $\mathrm{t} \sim 1.2-2 \mathrm{hr}$, the results indicated a gradual transition from mineral scaling

224 to particulate fouling. The transition was driven by the increase of $\mathrm{CaCO}_{3}$ crystals size, as apparent from the PVM images (Fig. $2 c$ at $t_{3}$ and $t_{6}$ ). The progress of the bulk crystallization process is also indicated by the linear increase in RBI at $\sim 1.2-2 \mathrm{hr}$. A surprising increase in permeate flux was observed at this stage. We attribute this trend reversal to further growth of the previously $(\mathrm{t} \sim 0.6-1 \mathrm{hr})$ deposited sub-micron crystals since the cake layer constructed of larger particles is more permeable and is more affected by shear-induced diffusion 230 (Chellappah et al., 2010). The flattening of the fouling layer electric resistance curve (Fig. 2a) further supports the transition to the deposition of a cake layer comprising larger particles and consequently larger average pore size with higher ion conductance.

In the third stage, $\mathrm{t} \sim 2-4 \mathrm{hr}$, our results suggest a complete shift to a particulate fouling regime. This was expressed in a milder decrease in flux with time relative to the $1^{\text {st }}$ stage and a small yet distinct reduction in the electrical resistance. The latter can be attributed to cake-enhanced concentration polarisation (CECP), which was previously shown to increase the conductance of the fouling layer (Antony et al., 2013). The steady increase in RBI at t 2-2.5 hr (fig. 2b) and the PVM images taken at $\mathrm{t} \sim 2-2.15 \mathrm{hr}$ (Fig. $2 \mathrm{c}, \mathrm{t}_{6} \& \mathrm{t}_{7}$ ) points at further growth of $\mathrm{CaCO}_{3}$ crystals in the bulk, which resulted in the formation of a cake layer. At $\mathrm{t} \sim 2.5-4 \mathrm{hr}$, the RBI (fig. 2b) decreased per a decrease in the particle concentration in the feed seen in the 
241 PVM image recorded at $\mathrm{t}=3.25 \mathrm{hr}$ (S22). This is due to the build-up of particles on the

242 membrane surface, as the further decrease in flux suggests. The radically different

243 consequences to filtration performance associated with the different fouling regimes have

244 prompted us to conduct additional experiments to differentiate between scaling and

245 particulate fouling as described below.

\section{$246 \quad$ 2.2. $\mathrm{CaCO}_{3}$ mineral fouling under low supersaturation}

247 To reinforce our findings on the signals caused by $\mathrm{CaCO}_{3}$ mineral scaling, we simulated low

248 supersaturation in the feed to suppress bulk crystallization. This was done by extending the 249 intervals between scaling salt additions to $1 \mathrm{hr}$ or more. At $\mathrm{t} \sim 0-0.5 \mathrm{hr}$, the normalized flux 250 and electrical resistance (Fig 3a) development were similar to the previous experiment, as the 251 flux decreased sharply by $9.0 \%$ and the electrical resistance of the fouling layer increased. 252 At the same time, the RBI (Fig 3b) remained unchanged for $\mathrm{t}<0.5 \mathrm{hr}$, confirming that no 253 particles were present in the bulk - an indication of heterogenous mineral scaling. At $\mathrm{t}>0.5$ $254 \mathrm{hr}$, the RBI increased due to the emergence of nanoparticles, too small to be captured as 255 images by the in-line microscope. In the high supersaturation experiment, a second aliquot 256 of scalants was added at this point, resulting in the continuation of the flux decline in the 257 same trend. This time, however, the flux decline was flattened with the increase in RBI, which 258 can be attributed either to fouling by nanoparticles or to a slower scaling formation due to 259 competition with the nanoparticles' surface and lower bulk supersaturation. Accordingly, the 260 increase in electrical resistance was flattened again, further demonstrating the high sensitivity 261 of this method to the type of mineral fouling. At $\mathrm{t}=1 \mathrm{hr}$, a second dose of scalants was added, 262 initiating a complete transition to particulate fouling. This was indicated by the in-line 

decrease in fouling layer electrical resistance, as in the previous set of experiments. This time, however, post-filtration SEM imaging provided additional information.

SEM images of the $\mathrm{CaCO}_{3}$ crystals deposited on the membrane surface (Fig 3c) further reinforced our hypothesis regarding the dominant fouling mechanism. The deposited particles had crystalline rhombohedral sharp and straight edges - typical of calcite polymorphs (Andritsos et al., 1997), the most stable form of $\mathrm{CaCO}_{3}$. The large particles (>15 $\mu \mathrm{m}$ ) appearing in the cross-sectional image (Fig 3c) and overshadowed in the bulk suspension 271 imaging by smaller particles (S11- $\left.\mathrm{T}_{2-3}\right)$ suggest lateral growth on the membrane surface, 272 affirming the assumption of heterogenous crystallization. According to the SEM images, 273 scaling was developed as separate 'islands' that grew on the membrane and blocked the


c)
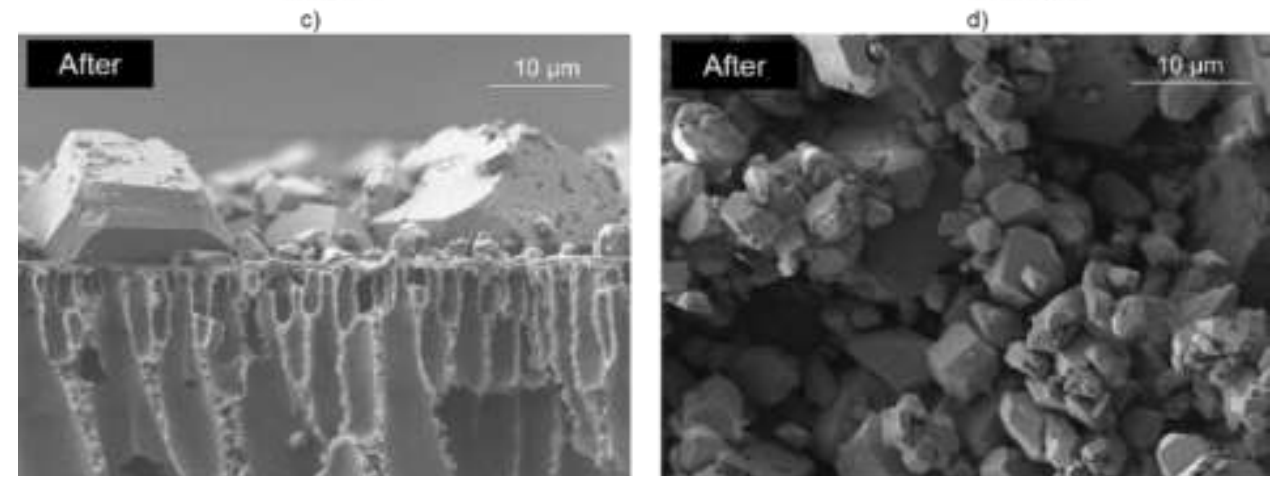

Figure 3: Data recorded during and after nanofiltration of solutions having low supersaturation with calcium carbonate (a) Permeability-(O) and membrane resistance-( $\square$ ) $[\Omega]$ (b) RBI evolution, SEM images; (cross-sections; (c), and top view after filtration (d), with 2500x magnifications,); over the filtration time $[\mathrm{h}]$ for simulated low supersaturation $\mathrm{CaCO} 3$ scaling. SEM images show crystalline particles of various sizes; large particles $(>15 \mu \mathrm{m})$ heterogeneously grew laterally on the membrane surface due to surface crystallization/scaling before homogenous crystallization. Smaller particles $(<5 \mu \mathrm{m})$ are due to homogenous crystallization. The extended graphs until $24 \mathrm{hr}$ time can be found at S20. 

transfer of water and ions. The smaller $(<5 \mu \mathrm{m})$ particles seen in between (Fig 3c) and on top

275 of (Fig 3d) the larger particles corroborate our finding that particulate fouling took place after

276 mineral scaling. The results of the particulate fouling experiment described below confirm

277 that the smaller particles originated from bulk crystallization.

\section{$278 \quad 3.3 . \quad$ Particulate fouling by $\mathrm{CaCO} 3$ crystals}

279 To reinforce our interpretations regarding the signals caused by particulate fouling of $\mathrm{CaCO}_{3}$

280 precipitates, we induced homogenous bulk crystallization in the feed tank before initiating 281 filtration. This was done by adding 7 aliquots of $8 \mathrm{mmol}\left(\mathrm{CaCl}_{2} / \mathrm{NaHCO}_{3}\right)$ in intervals of 20 282 minutes, as in the high supersaturation experiments. The crystals' growth was evident from 283 the monotonic increase in RBI (Fig. 4b) at $\mathrm{t} \sim 2.2-2.9 \mathrm{hr}$. The sharp increase in RBI after 284 filtration started may be due to the change in flow around the probe in the feed tank. As seen 285 in Fig. 4a, the normalized flux increased by 4-6\%, while the electrical resistance of the 286 membrane and fouling layer decreased by $\sim 0.8 \Omega$. These signals are an amplified response to 287 particulate fouling (as observed in the final fouling stage, section 3.1), i.e., negligible addition 288 to the hydraulic resistance and cake enhanced concentration polarization. The latter is also 289 supported by the decrease in observed salt rejection (Fig. 4c). The SEM images (Fig 4: d \& 290 e) taken after filtration show relatively homogeneous size distribution of the crystals, typical 291 of bulk crystallization. The large crystals, indicative of their lateral growth on the membrane surface (as observed in Fig. 3c \& d) are not seen in this case. The porous structure of the 


\subsection{Rapid increase of Calcium phosphate supersaturation}
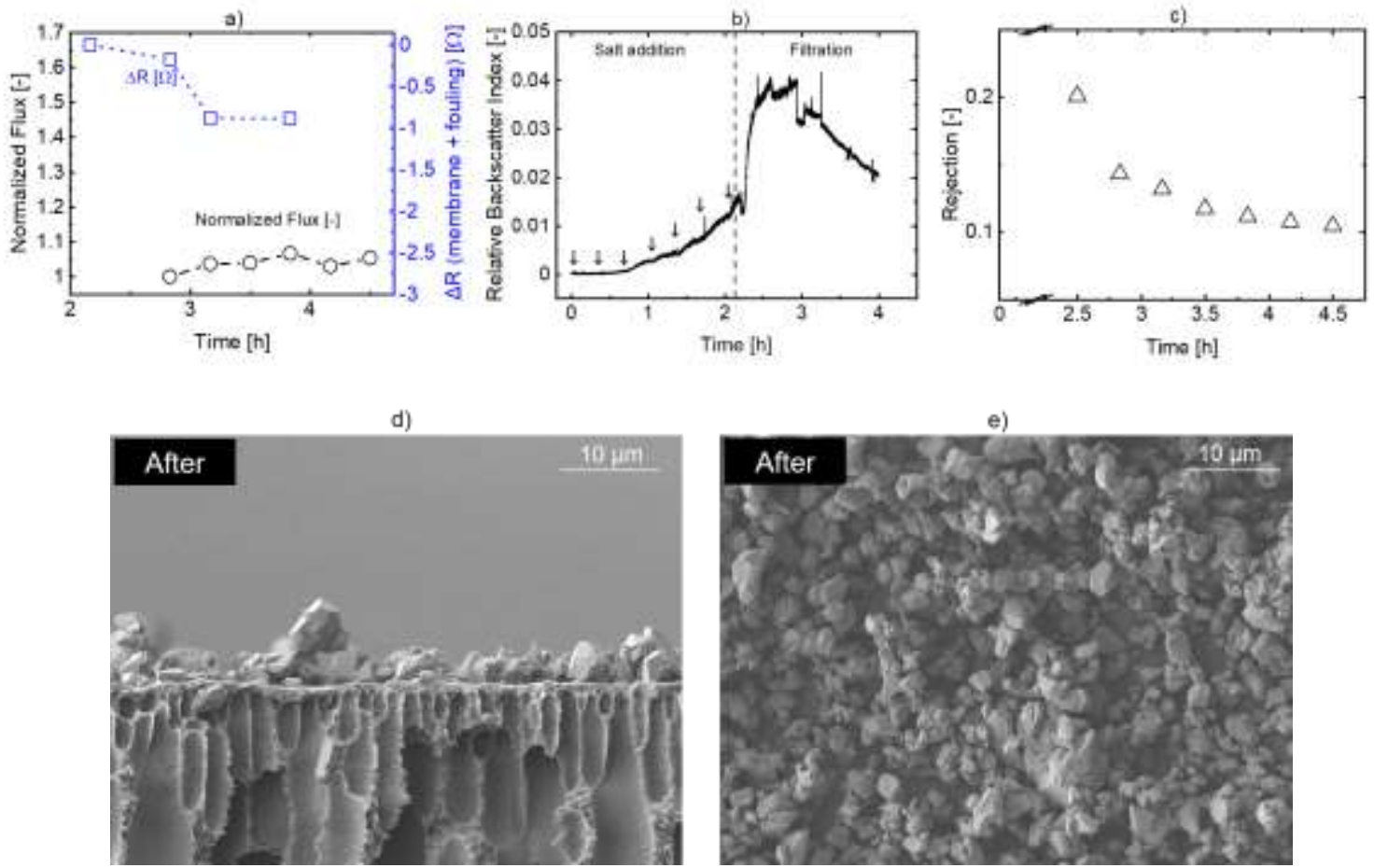

Figure 4: Data recorded during nanofiltration of calcium carbonate particle suspension (a) permeability$(\mathrm{O})$ and membrane resistance-( $\square$ ) $[\Omega]$; (b) RBI [-] evolution; (c) salt rejection- $(\Delta)$; SEM images (Cross Section (d), top view(e), with 2500x); over the filtration time [h] in $\mathrm{CaCO} 3$ simulated bulk crystallizationcake filtration.

The trend of normalized flux vs. time (Fig. 5a) during filtration of synthetic effluent

supersaturated with $\mathrm{Ca}-\mathrm{P}$ was similar to that observed for $\mathrm{CaCO}_{3}$. Similarly, this trend is consistent with data obtained from repeat experiments (S17), indicating the reproducibility of our experiments. The trend in electrical resistance of the fouling layer was also similar; however, the time synchronization of this signal with the flux signal differs in the case of $\mathrm{Ca}$ stage ( $\sim 0-1 \mathrm{hr}$ ) in which the flux decreased sharply (43\%), a second stage in which the flux increased ( $\sim 1-1.25 \mathrm{hr}$ ), and a third stage in which the flux decreased gradually (by 
$\sim 14 \%$ ). At the same time, the fouling layer electrical resistance was negligible in the first 0.5

Although the trends in flux and EIS are similar between $\mathrm{CaCO}_{3}$ and $\mathrm{Ca}-\mathrm{P}$, the signals are synchronized differently in time, pointing at a different fouling mechanism.

By combining flux and EIS (Fig. 5a) with real-time microscopy (Fig. 5b \& c), we were able
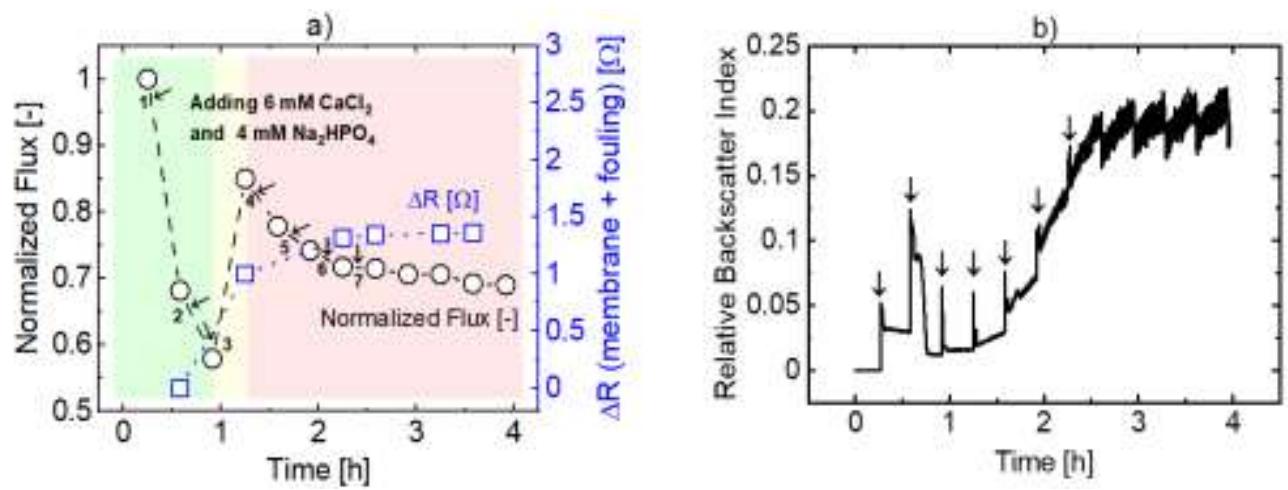

c)
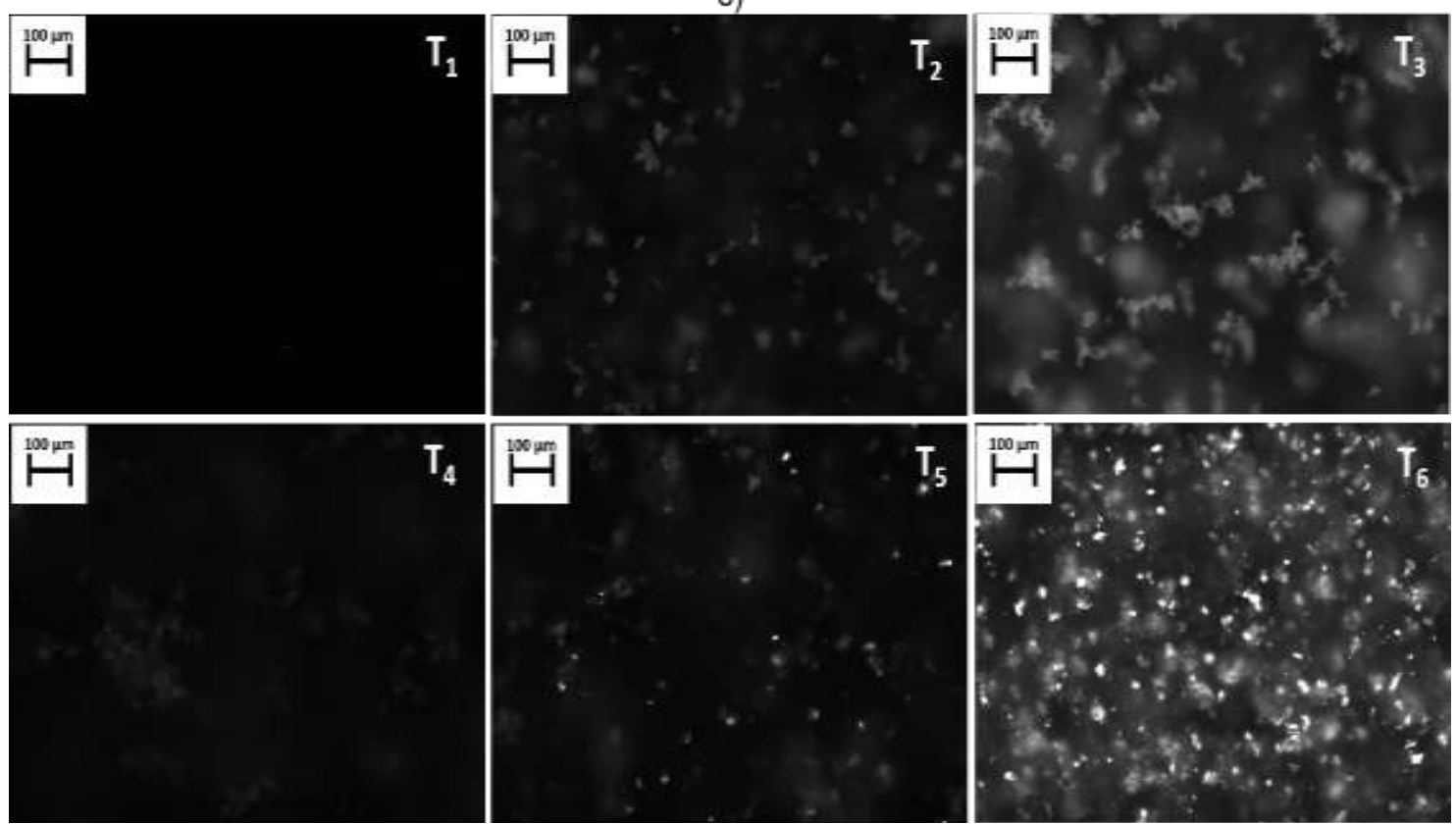

Figure 5: Data recorded during nanofiltration of solutions highly supersaturated with calcium phosphate (a) permeability-(O) and membrane resistance- $(\square)[\Omega]$; (b) RBI [-] evolution; (c) and in-line real-time microscope images at different time stages of filtration.

to pinpoint the mechanisms underlying membrane fouling by $\mathrm{Ca}-\mathrm{P}$ minerals, as it evolved 
313 during the nanofiltration experiment. Immediately after the first salt addition, the RBI (Fig.

$3145 b)$ increased, implying that bulk precipitation already occurred at this early stage. This

315 conclusion was supported by an independent experiment (Fig. S10), in which we found that

316 Ca-P precipitation starts at close to zero (0.0) supersaturation of ACP and with a very short

317 induction time ( $50-100$ seconds). The sharp flux decrease in this initial stage is thus

318 attributed to the accumulation of sub-micron, highly hydrated, amorphous particles, which

319 created a fouling layer of high hydraulic resistance. Ions, in contrast, could easily pass

320 through this layer, indicating its porosity. After $0.5 \mathrm{hr}$ (before the $2^{\text {nd }}$ salt addition), the real-

321 time imaging (Fig. 5c-t 2 ) reveals aggregates of particles with distinct 'fluffy' morphology and

322 low light reflectance, thus affirming bulk precipitation of amorphous particles. After the $2^{\text {nd }}$

323 salt addition, the number of particles and size of the aggregates in the bulk further increase

324 (Fig. 5c- $\mathrm{t}_{3}$ ), leading to an additional decrease in flux. Following the $3^{\text {rd }}$ salt addition, the

325 normalized flux increased from its minimum at 0.57 back to 0.85 , while the electrical

326 resistance increased sharply, indicating a change in the morphology of the layer. Indeed, the

327 real-time particle imaging revealed a transition from amorphous precipitants (Fig. 5c, $\mathrm{T}_{1-3}$ ),

328 first to a less 'flaky' and more interconnected aggregates (Fig. 5c $\mathrm{T}_{4}$ ), and then to a mixed-

329 phase with crystalline components having a defined shape and high reflectance (Fig. $5 c$ T5-

330 6). It should be noted that the circulating feed solution is in direct contact with both the

331 suspended particles, which were captured by the real-time imaging system and the particles

332 in the fouling layer. Therefore, particle growth and phase transition observed in the bulk are

333 also expected in the fouling layer, where these processes can be accelerated by concentration

334 polarization. After this transition, the RBI increase and particle imaging indicate crystal

335 growth in the bulk, corresponding to typical cake filtration, i.e., slow reduction in flux and

336 negligible change in electrical resistance. 


\subsection{Slow increase of calcium phosphate supersaturation}

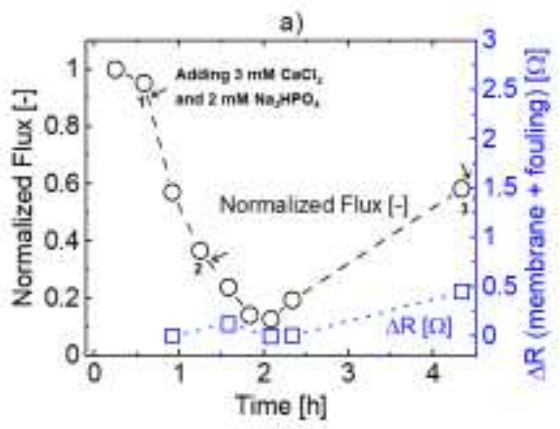

c)

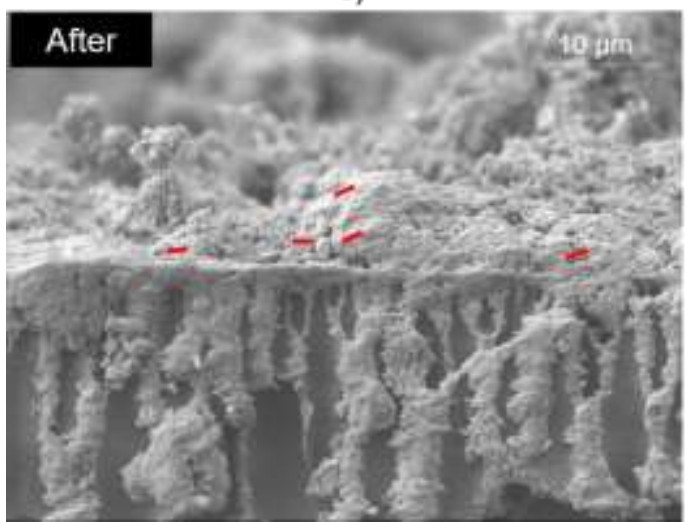

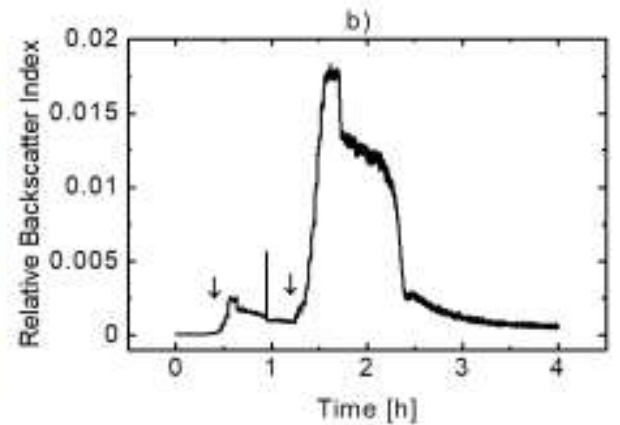

d)



Figure 6: Data recorded during and after nanofiltration of solutions having low supersaturation with calcium phosphate (a) Permeability-(O) and membrane resistance-( $\square$ ) $[\Omega]$ (b) RBI evolution, SEM images; (cross-sections; (c), and top view (d) after filtration with 2500x magnifications,); over the filtration time $[\mathrm{h}]$ for slow increase of Ca-P supersaturation scaling. Small red strips indicate flat surface spots. Bulk crystallization is dominant and subsequent particles deposition - forming impermeable cake layer. The extended graphs until $24 \mathrm{hr}$ time can be found at S21.

To further understand the initial, low supersaturation stage of Ca-P fouling and to test our interpretation regarding the mechanism, we conducted another fouling experiment, where we increased the duration of low supersaturation. This was done by (1) adding half the amount of salt in every aliquot; (2) extending the intervals between salt aliquot to avoid fast crystallization, and; (3) splitting each aliquot to 10 equal small doses ( 2 min. interval) to avoid high local concentration. This procedure resulted in fouling effects similar to those described in the initial stages of the previous section, yet more 'stretched' in time, allowing us to explore this stage with better time resolution.

The results reinforce our understanding of $\mathrm{Ca}-\mathrm{P}$ fouling under slow supersaturation increase and align with the results obtained for the rapid supersaturation increase (section 3.4). After 
the $1^{\text {st }}$ salt addition, the RBI (Fig. 6b) increased after a very short induction time, as before, then gradually decreased due to aggregation, and increased yet again after the $2^{\text {nd }}$ salt addition. The RBI evolution supports the premise of $\mathrm{Ca}-\mathrm{P}$ bulk precipitation as a primary fouling initiator. Due to the prolonged dominance of small particles in the circulating feed, the flux dramatically decreased by $64 \%$ and $86 \%$ after the $1^{\text {st }}$ and $2^{\text {nd }}$ additions, respectively, despite the lower amount of scalants added compared to the rapid supersaturation increase. This demonstrates the significant role of fouling layer morphology, influenced by the rate at which supersaturation increases. At the same time, the low and relatively constant electrical resistance value during the $1^{\text {st }} 2.5$ hrs supports the premise of a porous layer with good ion conduction and poor water conduction properties.

The results obtained at longer times $(>2.5 \mathrm{hrs})$, during the slow increase of Ca-P supersaturation, further support our interpretation of the results obtained during the rapid supersaturation increase (section 3.4). Both the flux and EIS increased, showing the same trend as in section 3.4, yet after a longer time, due to lower concentrations of $\mathrm{Ca}$ and $\mathrm{P}$. With this improved time resolution, it is visible that both the flux and EIS signals increased at the same time (Fig. 6a), reinforcing the premise of a morphological change in the fouling layer. We thus pose that dehydration and crystallization processes have condensed the layer, causing deswelling, which opened channels for faster water transport but reduced the surface available for ion transport. Condensation and dehydration of aggregates were previously recorded during the aging of amorphous Ca-P (Xie et al., 2014). Evidence for a phase transition can also be seen in the SEM images taken post-filtration. In both cross-sectional (Fig. 6c) and top view (Fig. 6d), flat surfaces (indicated by small red strips) of higher crystallinity can be spotted within the dense semi-porous fouling layer. Precipitant seen below the membrane surface is probably minerals that were smeared on the cross-section when cutting the membrane in preparation for SEM imaging. Intra-pore fouling is not likely 
373 because the rejection of hydrogen phosphate by this membrane is very high $(>90 \%$ see 374 independent experiment in S24). In this stage, the drop in RBI indicates aggregation of small 375 particles, which is a precursor for Ca-P phase transformation and crystal growth (Čadež et 376 al., 2018; Xie et al., 2014).

\subsection{Particulate fouling by Ca-P crystals}

379 To isolate the effect of fouling by the more crystalline Ca-P phase, we induced bulk 380 precipitation in the feed tank by adding 7 aliquots of scaling salts $\left(\mathrm{CaCl}_{2} / \mathrm{Na}_{2} \mathrm{HPO}_{4}, 6\right.$ and 4 mmol, respectively), at 20 minutes interval prior to the filtration step. After the first two

382 additions, the RBI signal (Fig. 7b) sharply increased due to the rapid formation of small 383 particles. After the third addition, the RBI decreased due to aggregation followed by 384 crystallization, as was also captured by the in-line imaging system (S14-T 3$)$. The RBI remained low until filtration started (apart from local spikes on salt additions), indicating that no secondary nucleation has occurred. The RBI increased with the beginning of filtration

387 (and the end of salt additions), likely due to shear forces causing the aggregates to break. As 388 expected in fouling by large particles, the flux and electrical resistance (Fig. 7a) (9\% and $\Delta \mathrm{R}$ $389=-0.25 \Omega$ respectively) slightly decreased (9\%). The decrease in salt rejection (Fig. $7 \mathrm{c}$ ) 390 further supported the occurrence of CECP. Overall, the trends in RBI, flux, and electrical 391 resistance recorded during this induced fouling by Ca-P matches our interpretation of the 392 final stage during the rapid increase of Ca-P supersaturation (section 3.4).

The SEM images (Fig. 7d\&e) reveal the morphology of the Ca-P precipitants and the fouling layer they have formed on the membrane surface. A mixed layer is seen, containing 
amorphous-looking aggregates, together with mature crystal platelets. The cross-sectional image (Fig 7d) reveals significant variations in the layer thickness that can be attributed to its heterogeneity. This heterogeneity is visible in the top-view image (Fig. 7e), also showing the contrast between the two phases. Compared to the fouling layer seen after the slow increase in Ca-P supersaturation (Fig. 6c), the amorphous phase is similar but seems less fouling.

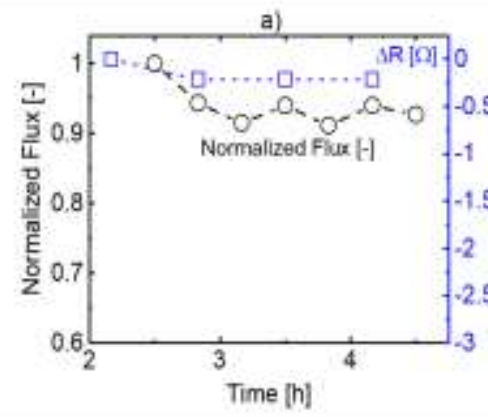

d)

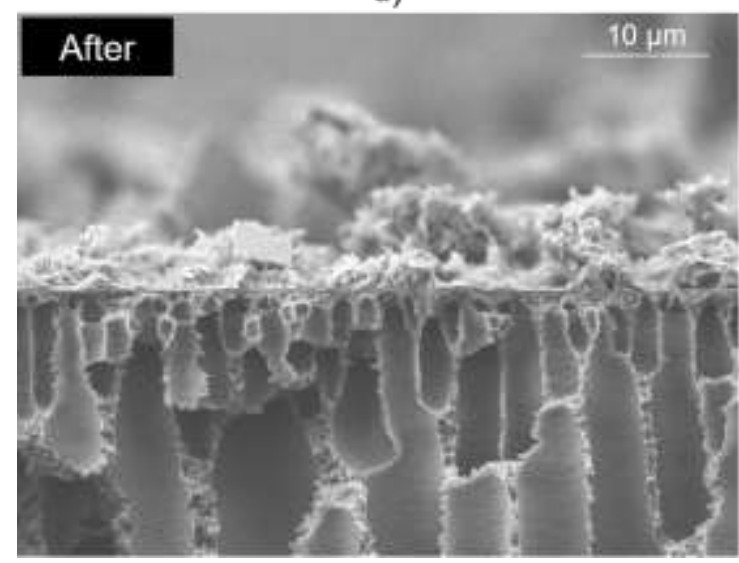



e)

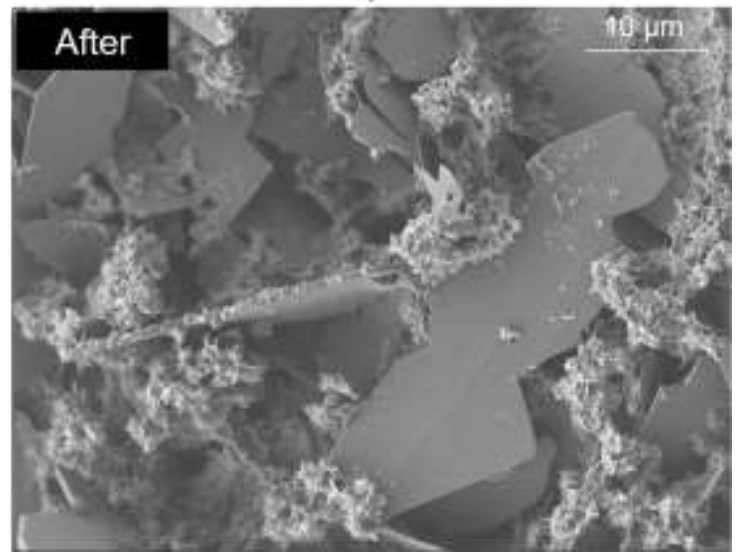

Figure 7: Data recorded during nanofiltration of calcium phosphate particle suspension (a) permeability$(\mathrm{O})$ and membrane resistance-( $\square$ ) [ $\Omega]$; (b) RBI [-] evolution; (c) salt rejection- $(\diamond)$; SEM images (Cross Section (d), top view(e), with 2500x); over the filtration time [h] in Ca-P simulated bulk crystallizationcake filtration.

405 4. Summary and Conclusions 
406 In this work, we studied membrane fouling by $\mathrm{CaCO}_{3}$ and $\mathrm{Ca}-\mathrm{P}$ minerals, using a novel 407 combination of real-time probing techniques: in-line particle imaging and EIS. This 408 combination was found highly useful, enabling us to uncover scaling mechanisms and 409 distinguish between them. Using these methods to study fouling by other minerals, such as 410 silica or iron oxides, will likely result in further insights. Complementary data gathered from 411 iC PVM, EIS, flux measurement, and post-filtration SEM imaging was used to reconstruct 412 how morphological changes induced by, e.g., aggregation, particle growth, and 413 crystallization determine the development of mineral fouling and its impact on filtration. The 414 morphological changes were found to depend on the mineral type, filtration time, and rate of 415 supersaturation increase.

416 For $\mathrm{CaCO}_{3}$ (Fig. 8a), the results imply that upon the increase in supersaturation, 417 heterogeneous precipitation on the membrane surface began, forming impermeable scaling 418 'islands' on the membrane surface. Consequently, the surface available to the transport of 419 both water and ions decreased. Upon further increase in supersaturation, the crystalline 420 scaling islands grew towards the sides and the top, further reducing flux and ion conductance.

421 At the same time, sub-micron particles started to form via bulk precipitation. Deposition of 422 these small particles between the scaling islands decreased the water flux but had a negligible 423 effect on ion passage. With further supersaturation increase and longer filtration time, the 424 surface area of the suspended particles gradually increased (with their size and number) until 425 it overshadowed the surface area of the scaling islands. This marked a transition from a 426 scaling regime to a particulate fouling regime. At the same time, the particles in the fouling 427 layer also grew (some possibly sheared of the membrane surface), thus enabling faster water 428 transport and partial recovery of the water flux. With further increase in supersaturation, 429 larger particles formed in the bulk deposited on and between the scaling islands, slightly 

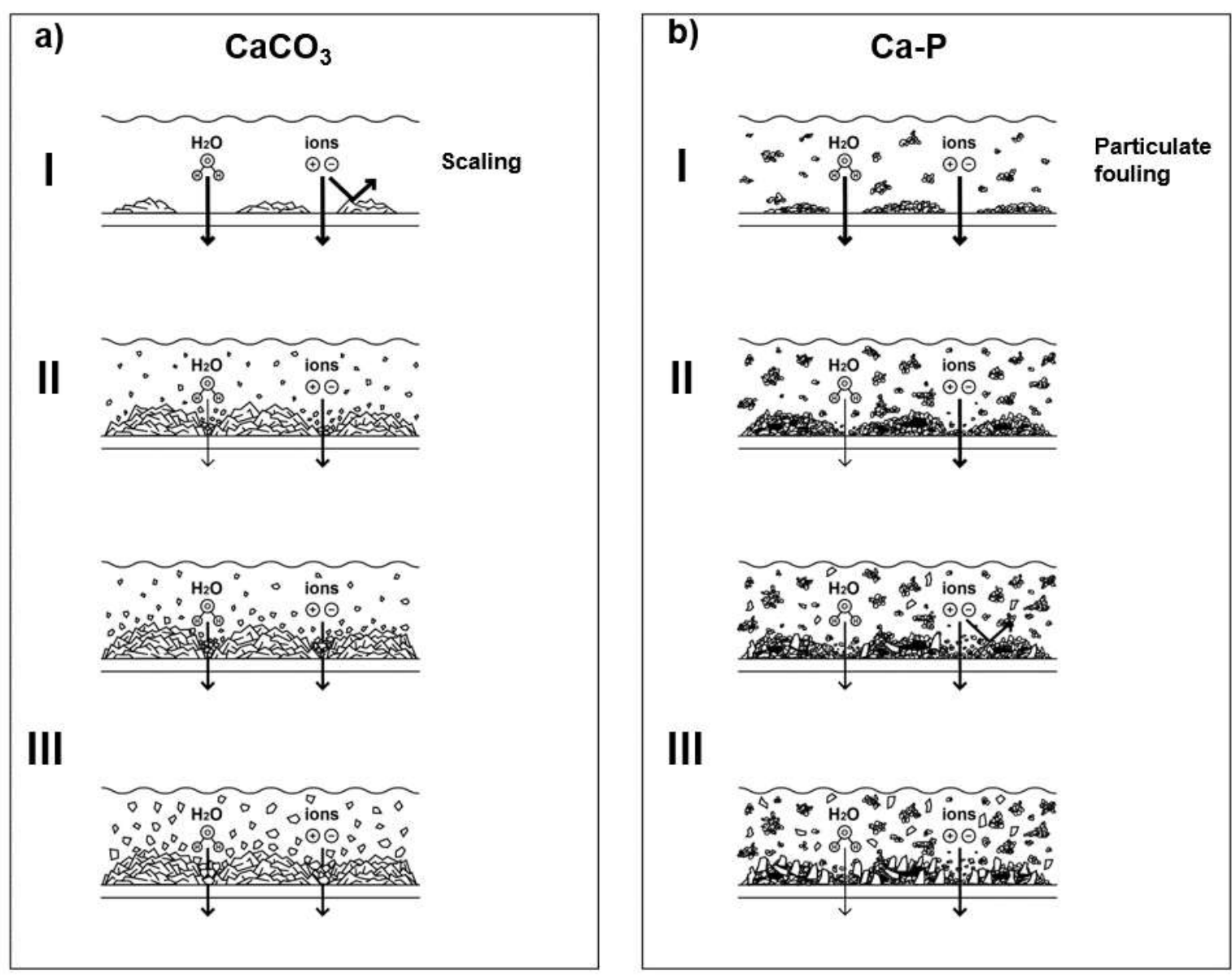

Figure 8: Illustration of the proposed mechanism of mineral fouling evolution with time based on the realtime monitoring and post-filtration microscopy (a) $\mathrm{CaCO}_{3}$ scaling evolution stages initiated with scaling/surface crystallization and transforms to particulate fouling; (b) Ca-P fouling evolution stages, initially with amorphous particulates and transforms into crystalline particulates.

For Ca-P (Fig.8b), the results imply that mineral fouling is initiated by bulk precipitation, occurring at very low supersaturation with almost no induction time. At the conditions studied, the precipitant is initially composed of amorphous, highly hydrated sub-micron

436 particles, which deposit on the membrane. Consequently, a porous fouling layer is formed,

437 hindering water transport but allowing ions to pass through. With the increase in supersaturation and at longer filtration time, the smaller particles aggregated, followed by 
439 dehydration and consolidation of the amorphous Ca-P, as part of its aging process. Some of 440 the aggregates may have detached from the surface by sheer force. This resulted in a dense 441 layer with holes and cracks, allowing faster ion passage but hindering water transport. After 442 a further increase in supersaturation and filtration time, the phase transition progresses, and 443 plate-shaped crystals appear. These crystals deposit and accumulate on the membrane, 444 forming a top cake layer that inhibits water transport, but increased electrical conductivity 445 through cake enhanced concentration polarization of ions.

446 Our findings have practical implications for the control and mitigation of mineral fouling, 447 which is essential for obtaining a high recovery in wastewater effluent nanofiltration and 448 reverse osmosis. We show evidence that under typical effluent filtration conditions, ACP 449 formed in the retentate solution controls the initial stages of $\mathrm{Ca}-\mathrm{P}$ fouling. Therefore, 450 modifying the membrane surface is not expected to contribute to scaling mitigation 451 significantly. We also observed that ACP starts precipitating at a very low supersaturation 452 level and with practically no induction time, making the saturation index a practical scaling 453 control parameter. In contrast, $\mathrm{CaCO}_{3}$ fouling is initially controlled by surface scaling, which 454 starts after a significantly shorter induction time compared to bulk precipitation. Compared 455 to $\mathrm{CaCO}_{3}$ scaling, Ca-P fouling is more reversible and could be more easily controlled by 456 crossflow cleaning or backwash. Acid cleaning should also be more effective for a porous 457 layer (as compared to the crystalline scaling layer) since the liquid-solid contact area is 458 higher. Thus, $\mathrm{CaCO}_{3}$ scaling should be avoided. We found that when the retained solution 459 contains larger and more crystalline mineral particles, the effect of fouling on filtration 460 performance is less severe. This raises interesting possibilities to control mineral fouling by 461 introducing seeds at an intermediate filtration stage. In our future work, we plan to implement 462 and test this novel strategy. 
This work was funded by the Ministry of Science and Technology (MOST) Israel, under the

466 framework of German-Israeli Water Technology Research (Project: 8764961). We also thank

467 the Young Scientists Exchange Program (YSEP) of the BMBF-MOST Cooperation in Water 468 Technology Research.

\section{References}

Almuktar, S.A.A.A.N., Abed, S.N., Scholz, M., 2018. Wetlands for wastewater treatment and subsequent recycling of treated effluent: a review. Environ. Sci. Pollut. Res. https://doi.org/10.1007/s11356-018-2629-3

Andritsos, N., Karabelas, A.J., Koutsoukos, P.G., 1997. Morphology and structure of $\mathrm{CaCO} 3$ scale layers formed under isothermal flow conditions. Langmuir. https://doi.org/10.1021/la960960s

Antony, A., Chilcott, T., Coster, H., Leslie, G., 2013. In situ structural and functional characterization of reverse osmosis membranes using electrical impedance spectroscopy. J. Memb. Sci. https://doi.org/10.1016/j.memsci.2012.09.028

Antony, A., How, J., Gray, S., Childress, A.E., Le-clech, P., Leslie, G., 2011. Scale formation and control in high pressure membrane water treatment systems : A review. J. Memb. Sci. 383, 1-16. https://doi.org/10.1016/j.memsci.2011.08.054

Bannwarth, S., Trieu, T., Oberschelp, C., Wessling, M., 2016. On-line monitoring of cake layer structure during fouling on porous membranes by in situ electrical impedance analysis. J. Memb. Sci. https://doi.org/10.1016/j.memsci.2016.01.009

Bunani, S., Yörükoğlu, E., Sert, G., Yüksel, Ü., Yüksel, M., Kabay, N., 2013. Application 

of nanofiltration for reuse of municipal wastewater and quality analysis of product water. Desalination 315, 33-36. https://doi.org/10.1016/J.DESAL.2012.11.015

Čadež, V., Erceg, I., Selmani, A., Domazet Jurašin, D., Šegota, S., Lyons, D., Kralj, D., Sikirić, M., 2018. Amorphous Calcium Phosphate Formation and Aggregation Process Revealed by Light Scattering Techniques. Crystals 8, 254. https://doi.org/10.3390/cryst8060254

Chang, I.S., Lee, S.S., Choe, E.K., 2009. Digital textile printing (DTP) wastewater treatment using ozone and membrane filtration. Desalination. https://doi.org/10.1016/j.desal.2008.01.014

Chaussemier, M., Pourmohtasham, E., Gelus, D., Pécoul, N., Perrot, H., Lédion, J., CheapCharpentier, H., Horner, O., 2015. State of art of natural inhibitors of calcium carbonate scaling. A review article. Desalination. https://doi.org/10.1016/j.desal.2014.10.014

Chellappah, K., Tarleton, S., Wakeman, R., 2010. The porosity, permeability and restructuring of heterogeneous filter cakes. Chem. Eng. Technol. https://doi.org/10.1002/ceat.201000093

Chen, T., Neville, A., Yuan, M., 2006. Influence of Mg2 + on CaCO3 formation-bulk precipitation and surface deposition. Chem. Eng. Sci. https://doi.org/10.1016/j.ces.2006.04.007

Farhadkhani, M., Nikaeen, M., Yadegarfar, G., Hatamzadeh, M., Pourmohammadbagher, H., Sahbaei, Z., Rahmani, H.R., 2018. Effects of irrigation with secondary treated wastewater on physicochemical and microbial properties of soil and produce safety in a semi-arid area. Water Res. https://doi.org/10.1016/j.watres.2018.07.047 
510 Friedler, E., 2001. Water reuse - An integral part of water resources management: Israel as a case study. Water Policy. https://doi.org/10.1016/S1366-7017(01)00003-4

512 Garcia, X., Pargament, D., 2015. Reusing wastewater to cope with water scarcity: Economic, social and environmental considerations for decision-making. Resour.

Gilron, J., Hasson, D., 1987. Calcium sulphate fouling of reverse osmosis membranes: Flux

Conserv. Recycl. https://doi.org/10.1016/j.resconrec.2015.05.015

$$
\text { decline mechanism. Chem. Eng. Sci. https://doi.org/10.1016/0009-2509(87)80109-4 }
$$

Grandclément, C., Seyssiecq, I., Piram, A., Wong-Wah-Chung, P., Vanot, G., Tiliacos, N., Roche, N., Doumenq, P., 2017. From the conventional biological wastewater treatment to hybrid processes, the evaluation of organic micropollutant removal: A review. Water Res. 111, 297-317. https://doi.org/10.1016/J.WATRES.2017.01.005

Greenberg, G., Hasson, D., Semiat, R., 2005. Limits of RO recovery imposed by calcium phosphate precipitation. Desalination. https://doi.org/10.1016/j.desal.2005.04.026

Greenlee, L.F., Testa, F., Lawler, D.F., Freeman, B.D., Moulin, P., 2010. The effect of antiscalant addition on calcium carbonate precipitation for a simplified synthetic brackish water reverse osmosis concentrate. Water Res. https://doi.org/10.1016/j.watres.2010.02.024

Kaganovich, M., Zhang, W., Freger, V., Bernstein, R., 2019. Effect of the membrane exclusion mechanism on phosphate scaling during synthetic effluent desalination. Water Res. https://doi.org/10.1016/j.watres.2019.06.013

Kappel, C., Kemperman, A.J.B., Temmink, H., Zwijnenburg, A., Rijnaarts, H.H.M., Nijmeijer, K., 2014. Impacts of NF concentrate recirculation on membrane performance in an integrated MBR and NF membrane process for wastewater 
Klepetsanis, P.G., Koutsoukos, P.G., 1989. Precipitation of calcium sulfate dihydrate at constant calcium activity. J. Cryst. Growth. https://doi.org/10.1016/00220248(89)90164-4

Lee, S., Lee, C.-H., 2005. Scale formation in NF/RO: Mechanism and control, Water Science and Technology.

Lee, S., Lee, C.H., 2000. Effect of operating conditions on CaSO4 scale formation mechanism in nanofiltration for water softening. Water Res. https://doi.org/10.1016/S0043-1354(00)00142-1

Luo, Y., Guo, W., Hao, H., Duc, L., Ibney, F., Zhang, J., Liang, S., Wang, X.C., Ngo, H.H., Nghiem, L.D., Hai, F.I., Zhang, J., Liang, S., Wang, X.C., 2014. A review on the occurrence of micropollutants in the aquatic environment and their fate and removal during wastewater treatment. Sci. Total Environ. 473-474, 619-641. https://doi.org/10.1016/j.scitotenv.2013.12.065

Mangal, M.N., Salinas-Rodriguez, S.G., Dusseldorp, J., Kemperman, A.J.B., Schippers, J.C., Kennedy, M.D., van der Meer, W.G.J., 2021. Effectiveness of antiscalants in preventing calcium phosphate scaling in reverse osmosis applications. J. Memb. Sci. 623, 119090. https://doi.org/10.1016/j.memsci.2021.119090

Mohammad, A.W., Teow, Y.H., Ang, W.L., Chung, Y.T., Oatley-Radcliffe, D.L., Hilal, N., 2015. Nanofiltration membranes review: Recent advances and future prospects. Desalination 356, 226-254. https://doi.org/10.1016/J.DESAL.2014.10.043

Murgolo, S., Franz, S., Arab, H., Bestetti, M., Falletta, E., Mascolo, G., 2019. Degradation of emerging organic pollutants in wastewater effluents by electrochemical 

photocatalysis on nanostructured $\mathrm{TiO} 2$ meshes. Water Res. https://doi.org/10.1016/j.watres.2019.114920

Nghiem, L.D., Fujioka, T., 2016. Removal of Emerging Contaminants for Water Reuse by Membrane Technology, in: Emerging Membrane Technology for Sustainable Water Treatment. https://doi.org/10.1016/B978-0-444-63312-5.00009-7

Nir, O., Sengpiel, R., Wessling, M., 2018. Closing the cycle: Phosphorus removal and recovery from diluted effluents using acid resistive membranes. Chem. Eng. J. 346, 640-648. https://doi.org/10.1016/j.cej.2018.03.181

Nir, O., Trieu, T., Bannwarth, S., Wessling, M., 2016. Microfiltration of deformable microgels. Soft Matter 12, 6512-6517. https://doi.org/10.1039/c6sm01345g

Oren, O., Gavrieli, I., Burg, A., Guttman, J., Lazar, B., 2007. Manganese mobilization and enrichment during soil aquifer treatment (SAT) of effluents, the Dan Region Sewage Reclamation Project (Shafdan), Israel. Environ. Sci. Technol. 41, 766-772. https://doi.org/10.1021/es060576+

Oron, G., Gillerman, L., Buriakovsky, N., Bick, A., Gargir, M., Dolan, Y., Manor, Y., Katz, L., Hagin, J., 2008. Membrane technology for advanced wastewater reclamation for sustainable agriculture production. Desalination 218, 170-180. https://doi.org/10.1016/J.DESAL.2006.09.033

Rathinam, K., Oren, Y., Petry, W., Schwahn, D., Kasher, R., 2018. Calcium phosphate scaling during wastewater desalination on oligoamide surfaces mimicking reverse osmosis and nanofiltration membranes. Water Res. https://doi.org/10.1016/j.watres.2017.10.055

Roques, H., Girou, A., 1974. Kinetics of the formation conditions of carbonate tartars. 
Schäfer, A.I., Fane, A.G., Waite, T.D., 1998. Nanofiltration of natural organic matter: Removal, fouling and the influence of multivalent ions. Desalination 118, 109-122. https://doi.org/10.1016/S0011-9164(98)00104-0

Steiner, Z., Rapaport, H., Oren, Y., Kasher, R., 2010. Effect of surface-exposed chemical groups on calcium-phosphate mineralization in water-treatment systems. Environ. Sci. Technol. https://doi.org/10.1021/es101773t

Tong, T., Wallace, A.F., Zhao, S., Wang, Z., 2019. Mineral scaling in membrane desalination: Mechanisms, mitigation strategies, and feasibility of scaling-resistant membranes. J. Memb. Sci. https://doi.org/10.1016/j.memsci.2019.02.049

Tran, Q.K., Schwabe, K.A., Jassby, D., 2016. Wastewater reuse for agriculture: Development of a regional water reuse decision-support model (RWRM) for costeffective irrigation sources. Environ. Sci. Technol. https://doi.org/10.1021/acs.est.6b02073

Tzotzi, C., Pahiadaki, T., Yiantsios, S.G., Karabelas, A.J., Andritsos, N., 2007. A study of $\mathrm{CaCO} 3$ scale formation and inhibition in RO and NF membrane processes. J. Memb. Sci. https://doi.org/10.1016/j.memsci.2007.03.031

Van De Lisdonk, C.A.C., Van Paassen, J.A.M., Schippers, J.C., 2000. Monitoring scaling in nanofiltration and reverse osmosis membrane systems. Desalination. https://doi.org/10.1016/S0011-9164(00)00139-9

Voutchkov, N., 2011. Overview of seawater concentrate disposal alternatives. Desalination 273, 205-219. https://doi.org/10.1016/J.DESAL.2010.10.018

Wintgens, T., Melin, T., Schäfer, A., Khan, S., Muston, M., Bixio, D., Thoeye, C., 2005. 
The role of membrane processes in municipal wastewater reclamation and reuse.

Xie, B., Halter, T.J., Borah, B.M., Nancollas, G.H., 2014. Tracking amorphous precursor formation and transformation during induction stages of nucleation. Cryst. Growth Des. 14, 1659-1665. https://doi.org/10.1021/cg401777x membranes during municipal wastewater reclamation: Membrane autopsy results from

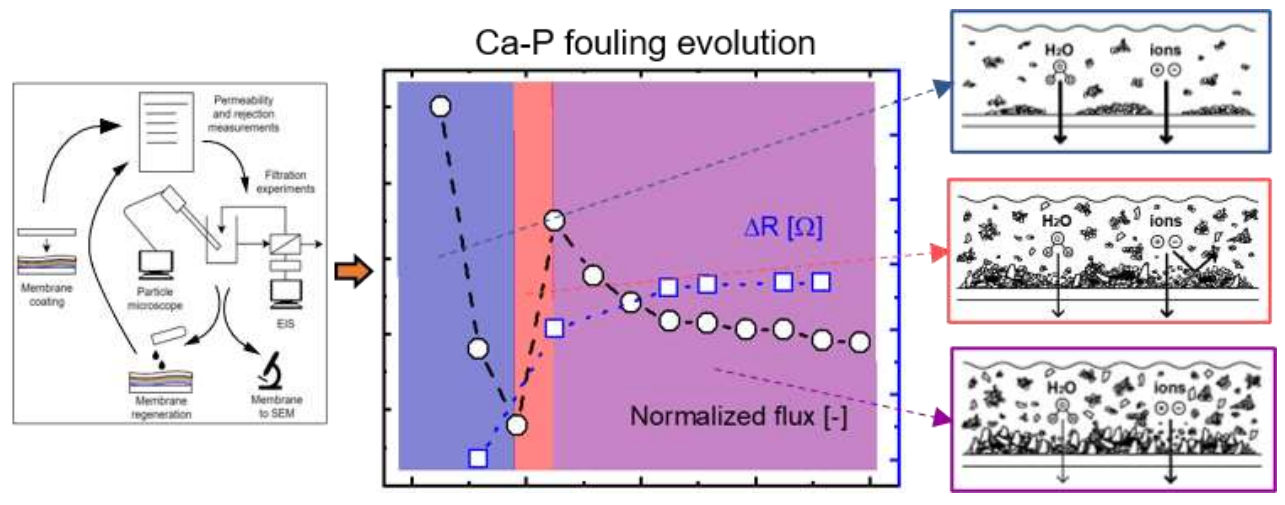

